\title{
Memory and law: what can cognitive neuroscience contribute?
}

\section{Citation}

Schacter, Daniel L, and Elizabeth F Loftus. 2013. Memory and Law: What Can Cognitive Neuroscience Contribute? Nature Neuroscience 16(2): 119-123.

\section{Published Version}

doi:10.1038/nn.3294

\section{Permanent link}

http://nrs.harvard.edu/urn-3:HUL.InstRepos:12561406

\section{Terms of Use}

This article was downloaded from Harvard University's DASH repository, and is made available under the terms and conditions applicable to Open Access Policy Articles, as set forth at http:// nrs.harvard.edu/urn-3:HUL.InstRepos:dash.current.terms-of-use\#OAP

\section{Share Your Story}

The Harvard community has made this article openly available.

Please share how this access benefits you. Submit a story.

Accessibility 
Memory and Law: What can Cognitive Neuroscience Contribute?

Daniel L. Schacter ${ }^{1} \&$ Elizabeth F. Loftus ${ }^{2}$

${ }^{1}$ Department of Psychology, Harvard University, Cambridge, Massachusetts, USA

${ }^{2}$ Department of Psychology and Social Behavior, University of California, Irvine, USA Correspondence:

Daniel L. Schacter

Department of Psychology

Harvard University

Cambridge, Massachusetts 02138

phone: (617) 495-3856

fax: (617) 496-3122

e-mail: dls@wjh.harvard.edu 


\begin{abstract}
A recent decision by the New Jersey Supreme Court has led to improved jury instructions that incorporate psychological research documenting that memory does not operate like a video recording. Here we consider how cognitive neuroscience could contribute to addressing memory in the courtroom. We discuss conditions in which neuroimaging can distinguish true and false memories in the laboratory, and note reasons to be skeptical about its use in courtroom cases. We also discuss neuroscience research concerning false and imagined memories, misinformation effects, and reconsolidation phenomena that may enhance understanding of why memory does not operate like a video recording.
\end{abstract}


In November 2003, Larry Henderson was accused of holding a gun on James Womble while another man shot Rodney Harper to death in a Camden, New Jersey apartment on New Year's Day of that year. Almost two weeks after the murder, Womble identified Henderson from a photo array. Womble again identified Henderson at trial, and Henderson was easily convicted of reckless manslaughter and aggravated assault amongst other changes. An open and shut case? Turns out not so. There were problems with Womble's seemingly convincing evidence: for instance, Womble failed to identify Henderson at the initial photo array, until the investigating officers intervened and exerted 'pressure' or 'nudging', and Womble had ingested crack cocaine and copious amounts of wine and champagne on the day of the murder.

Eventually this case (and a companion case) reached the New Jersey Supreme Court, which issued a ruling in 2011 that garnered wide public attention ${ }^{1}$. The decision showed a sophisticated appreciation of the problem of eyewitness memory and put in place a bold new solution. The case changed the legal standard for assessing eyewitness evidence to produce a better one - one that will more successfully deter inappropriate conduct by law enforcement and will help jurors to better evaluate evidence based on eyewitness memory. As a result of the Henderson case, defendants who can show some evidence of suggestive influences are entitled to a hearing in which all factors that might have a bearing on the eyewitness evidence are explored and weighed. If, after weighing the evidence presented at the hearing, the judge decides to admit the eyewitness evidence into trial, then the judge will provide appropriate, tailored jury instructions that will guide jurors on how to evaluate the eyewitness evidence. The new framework was created to serve the aim of not only protecting the government's 
interest in being able to present critical evidence at trial, but also the defendant's interest in being able to have the tools necessary to mount an effective defense.

Henderson's initial trial might have ended differently for him if he had this new legal standard in place at the time. He would have easily succeeded in showing suggestive influence, and if the judge decided to admit the eyewitness testimony despite the showing of suggestiveness, then Henderson's trial jury would have received “appropriate, tailored jury instructions" that contained critical information about the nature of human memory.

The tailored jury instructions ${ }^{2}$ were drafted over the next year and made public on July 19, 2012. From a scientific point of view, they are a vast improvement over any prior jury instructions on eyewitness evidence. The eyewitness instruction, coming from the judge, tells jurors that: "human memory is not foolproof. Research has shown that human memory is not at all like a video recording that a witness need only replay to remember what happened. Human memory is far more complex (p. 2)." Later on, the instructions urge jurors to consider various factors that could affect the eyewitness testimony, and provide explicit information on how to think about those factors. For example, in cases involving the identification of a stranger of a different race, the instructions state: "You should consider that in ordinary human experience, people may have greater difficulty in accurately identifying members of a different race (p.5)." As another example, in cases involving a great deal of stress or fright on the part of an eyewitness, the instructions state: "Even under the best viewing conditions, high levels of stress can reduce an eyewitness's ability to recall and make an accurate identification (p.3).”

What is impressive about these instructions is that unlike past ones that might have told jurors that they could take into account the state of mind of the witness, or the cross racial nature 
of the identification, the new instructions educate the juror about how to take these factors into account. The jurors were previously left to their intuitions about the factors, and many of those intuitions are unsupported or even contradicted by scientific evidence ${ }^{3,4}$. Many jurors will thus enter the deliberations with the erroneous belief that stress makes memory exceptionally accurate or that cross race identifications are just as accurate as same race ones ${ }^{3}$. But in New Jersey they'll become educated before making decisions that affect someone's liberty.

\section{Cognitive psychology, neuroscience, and the legal system}

The New Jersey court's decision relied on, and receives strong support from, decades of research from cognitive psychology showing that human memory does not work like a video recording; it is prone to various kinds of errors, distortions, and illusions (for recent reviews, see

${ }^{5-9}$ ). Such cognitive studies have established that eyewitnesses sometimes report confident but inaccurate memories and that post-event suggestions or misinformation can easily taint eyewitness memory ${ }^{10-12}$. There is also evidence that identifying members of a different race is typically more difficult than identifying members of the same race ${ }^{13}$, and that high levels of stress can impair the accuracy of eyewitness memory ${ }^{14}$. Highlighting the relevance of these findings to the courtroom, faulty eyewitness testimony was a factor in more than three-quarters of the first 250 cases nationwide in which DNA evidence exonerated individuals after conviction for crimes they did not commit ${ }^{15}$. Thus, in our view the New Jersey court devised its new jury instructions based on strong evidence from cognitive psychology that is clearly relevant to issues of pressing concern in the courtroom.

At the same time that cognitive studies have documented various kinds of memory errors and illuminated the conditions in which eyewitnesses are prone to them, neuroscience-based 
research has made considerable progress in unraveling the neural basis of memory. However, reference to such research is notably absent in the New Jersey court's decision. We do not believe that this omission reflects any kind of divergence between the broad view of human memory emerging from cognitive psychology on the one hand and cognitive neuroscience on the other. Although neuroscientists have tended to focus less on memory distortions and illusions than have cognitive psychologists, many neuroscience-based approaches to memory have embraced the idea that, far from operating like a video recorder, memory is a constructive, dynamic process that is sometimes prone to error ${ }^{16-19}$. Despite this broad agreement from the two approaches, attempts to identify and understand the brain mechanisms underlying memory, which are so central to cognitive neuroscience, are less directly related to the concerns of the court - which is charged with assessing the behavioral output of the memory system - than is work from cognitive psychology. While it is thus unsurprising that the New Jersey court did not cite neuroscience evidence in its decision and formulation of the new jury instructions, we think that it is important to consider the relation between memory as studied by neuroscience, and memory in the legal context: What contribution - if any - can neuroscience-based research on memory and the brain make to grappling with issues pertaining to memory in the courtroom? Does cognitive neuroscience have anything useful to tell jurors or other participants in the legal system about the likely accuracy of an eyewitness account, or about why "human memory is not like a video recording that a witness need only replay to remember what happened"?

\section{Distinguishing true and false memories with neuroimaging}

One way in which cognitive neuroscience research might inform the courts about memory concerns the difficult problem of distinguishing between true or accurate memories on the one hand and false or inaccurate ones on the other. Even though psychologists generally 
acknowledge that eyewitness memory is sometimes accurate and sometimes not, no definitive cognitive-behavioral methods exist for distinguishing true from false memories ${ }^{20}$. Thus, an exciting possibility is that neuroscientists could use brain imaging techniques, such as functional magnetic resonance imaging (fMRI) or event-related potentials (ERPs), to provide a clear answer as to whether a witness to a crime is recounting a true or a false memory.

During the past 15 years, a growing number of studies have shown that neuroimaging techniques, including fMRI and ERPs, can sometimes help distinguish true memories from false ones under laboratory conditions (for detailed review, see ${ }^{21-23}$ ). Many neuroimaging studies have used experimental paradigms in which participants initially study lists of semantically associated words or perceptually similar visual shapes. Later, experimenters scan the participants as they make old/new recognition decisions about three different kinds of items: old items that appeared earlier in the list; semantically or perceptually related new items that did not appear previously; or unrelated new items that did not appear previously. Participants in these experiments typically classify the old items as 'old' much more frequently than they classify the new, unrelated items as 'old', which constitutes evidence for true or veridical memory. The critical result is that participants also classify new, related items as 'old' much more frequently than new, unrelated items; these incorrect responses to the related items constitute evidence for false memories (e.g., ${ }^{24-27}$ ). Other neuroimaging studies have examined false memories that result from confusing perception and imagination ${ }^{28,29}$. For example, after seeing pictures of some objects (e.g., a photo of a car) and imagining others in response to a verbal cue (e.g., 'imagine a ball'), participants sometimes falsely remember that they saw a picture of an item that they only imagined (i.e., a ball). Still other neuroimaging studies have examined false memories that result from the presentation of misinformation after viewing an everyday event ${ }^{30-32}$. For example, after watching 
a man steal a woman's wallet, some subjects receive misinformation about what actually happened (e.g., the woman's arm was hurt during the robbery, rather than her neck), which they later remember as part of the original event.

Such studies have typically shown that many of the same brain regions are active for true memories (i.e., 'old' responses to old items) and false memories (i.e., 'old' responses to related, imagined, or suggested items), and have also documented some differences. For example, several studies have reported that brain regions involved in encoding or retrieving sensory-perceptual information tend to be more active during retrieval of true than false memories (e.g., ${ }^{24-27,29,32}$ ). Although the precise regions that distinguish true from false memories vary from study-to-study, the results are generally in line with the sensory reactivation hypothesis that emerged from earlier behavioral studies showing that true memories tend to be associated with retrieval of greater sensory and perceptual detail than false memories ${ }^{33}$. However, neuroimaging evidence for sensory reactivation comes from studies where researchers test memory shortly after exposure to target information. Given the tendency for recollection of sensory details to fade over time ${ }^{5,8}$, such effects would presumably be more difficult to detected at longer delays (i.e., weeks or months). Evidence also exists that regions within anterior prefrontal cortex, especially in the right hemisphere, tend to be preferentially activated for false as compared with true memories, perhaps signaling a role for anterior prefrontal cortex in memory monitoring or evaluation ${ }^{26,27}$, 34,35 .

In light of these and related findings ${ }^{21-23}$, it is tempting to imagine that the legal system could rely on neuroimaging to help determine whether an eyewitness is remembering accurately or not. However, there are several reasons to be skeptical about the use of neuroimaging evidence concerning true versus false memories in the courtroom. First, laboratory studies have 
generally used simple and easy-to-control materials, such as words and pictures, but it is unclear whether results from these studies generalize to the kinds of complex everyday events that are more typically encountered in the courtroom; indeed, a recent literature review reveals notable differences in the patterns of brain activity that are evident when people remember information presented in the laboratory versus autobiographical recollections of rich everyday experiences ${ }^{36}$. Second, neuroimaging studies of true vs. false memories typically use healthy young adult participants, whereas the courtroom typically includes more diverse populations. Third, as we noted above, such studies involve relatively brief delays between study and test, whereas courtroom cases usually involve much longer delays, and we do not yet know whether neuroimaging can distinguish true and false memories over delays that may involve months or more. Fourth, neuroimaging evidence for true-false memory differences comes from studies in which experimenters average brain activity across subjects and events, reflecting the fact that it is difficult to detect meaningful memory-related activity on single trials in individual subjects with techniques such as fMRI - yet that is precisely what courtroom cases demand. Researchers have made some progress in this regard by using pattern classifiers to analyze brain activity. In one study using such multivoxel pattern analysis ${ }^{37}$, participants studied faces of unfamiliar people and one hour later made old/new recognition judgments about previously studied faces as well as new faces that had not been previously studied. A classifier determined reliably whether individual participants subjectively experience a face as old or new. But the classifier could not reliably determine the objective status of the face - that is, whether it is in fact old or new which would be critically important in a courtroom setting. Similarly, neuroimaging studies that have examined the neural correlates of subjective confidence in memory have generally found that fMRI responses in various memory-related regions are heavily influenced by subjective 
confidence signals and less so by objective accuracy (for review, see $^{38}$ ). Fifth, even if neuroimaging develops to a point where it can provide reliable discrimination between true and false memories in individual cases, researchers would have to develop procedures to detect countermeasures that individuals might use to 'beat the test', yet we are not aware of any such procedures (for further discussion of this point and related concerns, see ${ }^{22}$ ).

While we expect that future advances in neuroimaging technology and analysis will eventually address these and other problems, they are presently significant ones that warrant a cautionary stance concerning the potential application of neuroimaging approaches to adjudicating questions about true versus false memories in the courtroom.

Several authors have expressed similar concerns regarding the potential use of neuroimaging techniques for detecting intentional deception in legal cases (for reviews, see ${ }^{39,40}$ ). Some laboratory studies have shown that regions within the prefrontal cortex tend to be more active when participants are lying than when they are telling the truth, likely reflecting the involvement of frontally-based executive processes during the manipulation and monitoring of information that is used to construct a $\operatorname{lie}^{41}$. One recent laboratory fMRI study showed that activity patterns in specific prefrontal regions could distinguish lies from truth telling with great accuracy in individual subjects ${ }^{42}$. However, that same study showed that when experimenters instructed participants to use countermeasures designed to beat the test, there was a dramatic reduction in the ability of fMRI responses to distinguish lies from truth. Because countermeasures are a significant concern in real-world settings, the authors of this study advised caution in applying fMRI-based lie detection outside the laboratory. This view is in line with previous cautionary arguments concerning the application of neural lie detection procedures to the courtroom, which point to such problems as the use of artificial laboratory tasks, inconsistent 
results across laboratories, lack of diversity in the subject populations tested (i.e., mainly healthy young adults), and an absence of evidence for the efficacy of neural lie detection procedures in real-world contexts ${ }^{39}$.

\section{Understanding the neural basis of true and false memories}

There is another way in which neuroscience research could potentially inform the legal system: by providing information about the neural mechanisms of memory errors and distortions that can enhance understanding of why it is that "human memory is not like a video recording." We noted earlier that neuroimaging studies have typically shown that many of the same brain areas are active during retrieval of true and false memories, including regions in prefrontal, parietal, and medial temporal cortices ${ }^{21-23}$. This finding could be useful for policy makers and judges in determining how to properly instruct juries about the reasons why false memories can be subjectively compelling: some of the same processes contribute to both true and false memories $^{8,9,21-23}$.

A nice example of this point comes from the finding ${ }^{43}$ that many of the same brain regions are active when participants accurately recognize visual shapes they viewed earlier and when they falsely recognize related (i.e., perceptually similar) shapes that they did not see earlier - but there is virtually no overlap in brain activity during accurate recognition of previously viewed shapes and false recognition of new, unrelated (i.e., perceptually dissimilar) shapes. The overlapping brain activity during true recognition of studied shapes and false recognition of related shapes likely reflects shared underlying processes. Participants make 'old' responses in these cases based on visual similarity or 'gist' information, which in this experimental paradigm refers to visual features that the related lure and the studied shapes share (e.g., similar line configurations, contours, and colors). Other studies have revealed that false memories sometimes 
result from relying on semantic or conceptual gist information ${ }^{5,6,8,9}$, such as when an individual inaccurately remembers studying a word (e.g., gold) that did not appear earlier but is semantically related to items that did appear earlier (e.g., bronze, silver, brass ${ }^{35}$ ). Neuroimaging data indicate that brain regions involved in semantic or conceptual processing can contribute to both true and false memories that are based on semantic information ${ }^{9,24,35}$. Such findings could be useful in guiding the crafting of jury instructions that could explain some of the reasons why false memories can occur.

Consider next the well-established finding that people sometimes confuse memory with imagination. Cognitive studies have shown, for example, that simply imagining an event that might have occurred in one's personal past can increase confidence or belief that the event actually occurred ${ }^{44}$, lead individuals to claim that they performed actions that they in fact only imagined $^{45}$, or result in the production of specific and detailed false memories of events that never actually happened ${ }^{7}$. Recent findings that have revealed striking neural overlap between memory and imagination can provide insight into the basis of such false memories. A growing number of neuroimaging studies have shown that instructing people to remember actual past events from their personal pasts and imagine hypothetical events that might occur in their personal futures recruits a common core network comprised of medial temporal lobes including hippocampus, medial prefrontal and medial parietal regions including retrosplenial cortex and posterior cingulate, and lateral temporal and lateral parietal regions (e.g. $\left.{ }^{46}\right)$. Moreover, neuroimaging studies have also shown that cognitive confusions between imagination and memory sometimes reflect increased activity in regions associated with visual imagery during memory encoding or retrieval ${ }^{28,29}$. These findings provide information concerning the neural 
basis of imagination and memory that could be helpful in further developing jury instructions that explain how and why the former can be mistaken for the latter.

\section{Misinformation effects and memory reconsolidation}

Similar considerations may apply to the well-established misinformation effect, which occurs when misleading suggestions or inaccurate information presented after an event result in distorted memory for the original event (for review, $\operatorname{see}^{11}$ ). Neuroimaging studies have added to our understanding of the misinformation effect by revealing that the effect reflects, in part, the degree or strength of the encoding of the original event versus degree of encoding of the subsequent misinformation. For example, in one study ${ }^{31}$ experimenters scanned participants while they viewed an initial event - a vignette consisting of a sequence of photographs -- and also during a subsequent misinformation phase when they viewed the same vignette but with several details altered from the original. The results showed that encoding-related activity in several brain regions during the original and misinformation phases, most notably in the left hippocampus and perirhinal cortex, predicts subsequent true or false memory: greater activity in these regions during the original event sequence is associated with accurate subsequent memory, whereas greater activity in these regions during the misinformation phase is associated with inaccurate subsequent memory ( $\mathrm{see}^{30}$ for similar results).

In an interesting recent twist on the standard misinformation paradigm that emphasizes social influences on memory accuracy ${ }^{47}$, participants who receive misinformation from other individuals who witnessed a movie with them sometimes commit memory errors despite warnings that the information that the others presented is untrustworthy. Critically, the effect is associated with increased recruitment of, and connectivity between, hippocampus and amygdala during encoding of the misinformation. In a non-social control experiment in which a computer 
algorithm presented the misinformation rather than other people, the hippocampal effect is again observed but the amygdala effect is not, suggesting that the latter may reflect specifically social influences on memory. These and the aforementioned neuroimaging findings complement and extend the results of behavioral studies of the misinformation effect ${ }^{11}$ and thus are of potential relevance to those attempting to instruct jurors concerning the nature and basis of misinformation effects.

As a final example of how neuroscience-based research might be relevant to understanding memory accuracy in legal settings, consider the phenomenon of reconsolidation, where reactivated memories enter a transient state of instability in which they are prone to disruption or change. Evidence for reconsolidation has come mainly from studies of non-human animals, where infusion of a protein synthesis inhibitor such as anisomycin into the lateral and basal amygdala during reactivation of an already consolidated auditory fear conditioning memory disrupts subsequent long-term retention of the auditory fear memory (for reviews, $\left.\operatorname{see}^{16,17,48}\right)$. Although experiments have demonstrated reconsolidation for various kinds of memories, they have also established boundary conditions on the phenomenon; for example, some evidence indicates that older memories are less susceptible to reconsolidation than are recent ones ${ }^{48}$ There are also some findings consistent with reconsolidation in humans (e.g., $\left.{ }^{49-51}\right)$. For example, in one study ${ }^{51}$ researchers induced fear conditioning by pairing a picture of a colored square with an electrical shock, such that presentation of the square eventually elicits a physiological fear response. A day later, reactivating the fear memory by presenting the colored square without shock 10 minutes before a series of extinction trials that repeatedly present the square without shock - an interval that falls within the time window in which researchers think that reconsolidation processes exert an effect - results in a long-lasting reduction of fear 
responses to the square, suggesting an effective rewriting of the original memory. By contrast, reactivating the fear memory six hours before the extinction procedure - a time interval that falls outside the reconsolidation window - does not have a long-lasting effect on fear reduction.

Reconsolidation may be a mechanism for updating memories with current information to keep them relevant ${ }^{17,48}$. In so doing, however, this updating mechanism may also contribute to changes and distortions in memory over time as a consequence of memory reactivation ${ }^{9,16,17}$. Recent behavioral evidence is consistent with this view, showing that reactivation can increase both true and false memories ${ }^{52}$. Note that a similar updating account may apply to the misinformation effect ${ }^{11}$, and there has been discussion of possible links between reconsolidation mechanisms and the misinformation effect ${ }^{17}$. Thus, although much work remains to be done to document and understand the neural basis of reconsolidation in humans, neuroscience-based research on reconsolidation potentially provides a foundation for understanding how memories can change over time. This phenomenon is clearly relevant to the legal system, especially in situations where suggestive questioning during the investigative process may introduce misinformation into a witness's memory. Consequently, research on reconsolidation could potentially add to work on misinformation in determining how to properly instruct juries concerning the nature of memory.

\section{Concluding comments}

Will modern neuroscience more generally, and brain scans more particularly, enter the courtroom anytime soon? They already have, in several ways. For example, some attorneys have used this type of evidence to mitigate the responsibility of defendants who commit crimes, arguing to the effect that 'a bad brain made him do it ${ }^{53}$. In one Florida murder case, where brain 
images of the defendant were introduced as evidence, jurors voted for a sentence of life without parole rather than the death penalty ${ }^{54}$.

But given the relatively short life of scientific explorations of neuroimaging and complex memories that might be true and might be false, we believe that it is wise to be skeptical now of current efforts to introduce neuroimaging data into the courtroom arena as evidence in individual cases where memory accuracy is at issue $\left(\right.$ see also $\left.^{55}\right)$. We have suggested that evidence from neuroscience, including neuroimaging studies, is consistent with and can broaden our understanding of evidence from cognitive psychology in showing that memory is a dynamic, constructive process that is sometimes prone to error and distortion. Thus, neuroscience evidence concerning memory, together with evidence from cognitive psychology, could play a role in educating jurors and other participants in the legal system generally about the nature of memory. However, we draw a distinction between such a general educational role and the application of neuroimaging data to individual cases. If the prosecution seeks to introduce fMRI evidence from a "memory truth detection" procedure to substantiate their claims that a witness is accurately remembering, or the defense wants to introduce other fMRI evidence to substantiate claims that a witness has a false memory, the court should apply the standards for admission of scientific evidence that apply in that jurisdiction, usually either the so-called Daubert or Frye standard as well as other evidentiary rules, to determine whether the evidence should reach the jurors. This is not only because of the uncertainties concerning the interpretation and reliability of fMRI evidence concerning true and false memories in individual cases that we discussed earlier, but also because people in general, and jurors in particular, are sometimes impressed with evidence from brain imaging and may be unduly influenced by it ${ }^{56,57}$. 
For example, presentation of fMRI images may increase judgments of the scientific credibility of actual and hypothetical findings even when the information that the images provide is largely redundant with text $\mathrm{t}^{56}$. In another study, mock jurors received trial information that included evidence that the defendant was lying about having committed a crime. When accompanied by brain scans, the lie detection evidence produces more guilty verdicts than when accompanied by other evidence such as polygraph or thermal facial imaging ${ }^{57}$. Although effects of brain scans on juror decision making are not always observed ${ }^{58}$, it is nonetheless noteworthy that in a recent murder case in which the defense sought to introduce fMRI evidence from a lie detection procedure to substantiate their claims that the defendant was telling the truth, the court did not allow the evidence after hearing expert testimony from both sides ${ }^{59}$.

Looking to the future, there may come a time where neuroscience evidence will be better developed and will more often see its day in court. When that happens, the legal system may want to take a lesson from New Jersey v Henderson, and put in place a bold new solution. If it mirrored Henderson, then any showing that the neuroscience evidence might be problematic could lead to a hearing, and, if admitted, would be accompanied by "appropriate, tailored jury instructions" that contain critical information about, for example, neuroimaging evidence and how jurors ought to think about it. In a case where the neuroimaging evidence pertained to distinguishing between true and false memories, we would hope that concerns like those we raised earlier would be brought to the attention of the jurors. Finding ways to educate jurors before they make decisions that affect someone's liberty, and more generally doing all that we can do to increase the chances of a just verdict, is an effort that deserves our sustained attention. 


\section{References}

1. State v. Henderson (2011), 208 N.J. 208.

2. Identification: In-Court and Out-of-Court Identifications, Criminal Jury Charges. (2012) http://www.judiciary.state.nj.us/criminal/charges/idinout.pdf

3. Schmechel, R.S., O'Toole, T.P., Easterly, C. \& Loftus, E.F. Beyond the Ken: Testing juror's understanding of eyewitness reliability evidence. Jurimetrics $J$. 46, 177-214 (2006).

4. Simon, D.J. \& Chabris, C.F. What people believe about how memory works: A representative survey of the U.S. population. PLoS One 6, e22757 (2011).

5. Brainerd, C.J. \& Reyna, V.F. The science of false memory (Oxford University Press, New York, NY, 2005).

6. Gallo, D.A. Associative illusions of memory (Taylor \& Francis, New York, 2006).

7. Loftus, E.F. Make-believe memories. Am. Psychol. 58, 867-873 (2003).

8. Schacter, D.L. The sevens sins of memory: How the mind forgets and remembers (Houghton Mifflin, New York, NY and Boston, MA, 2001).

9. Schacter, D.L., Guerin, S.A. \& St. Jacques, P.L. Memory distortion: An adaptive perspective. Trends Cogn. Sci. 15, 467-474 (2011).

10. Brewer, A. \& Wells, G.L. Eyewitness identification. Curr. Dir. Psychol. Sci. 20, 24-27 (2011).

11. Loftus, E.F. Planting misinformation in the human mind: A 30-year investigation of the malleability of memory. Learn. Mem. 12, 361-366 (2005).

12. Frenda, S.J., Nichols, R.M. \& Loftus, E.F. Current issues and advances in misinformation research. Curr. Dir. Psychol. Sci. 20, 20-23 (2011).

13. Meissner, C.A. \& Brigham, J.C. Thirty years of investigating the own-race bias in memory for faces: A meta-analytic review. Psychol. Public Policy Law 7, 3-35 (2001).

14. Deffenbacher, K.A., Borstein, B.H., Penrod, S.D. \& McGorty, E.K. A meta-analytic review of the effects of high stress on eyewitness memory. Law Human Behav. 28, 687-706 (2004).

15. Garrett, B.L. Convicting the innocent: Where criminal prosecutions go wrong (Harvard University Press, Cambridge, MA, 2011). 
16. Dudai, Y. The restless engram: Consolidations never end. Annu. Rev. Neurosci. 35, 227-247 (2012).

17. Hardt, O., Einarsson, E.O. \& Nader, K. A bridge over troubled water: Reconsolidation as a link between cognitive and neuroscientific memory research traditions. Annu. Rev. Psychol. 61, 141-167 (2010).

18. Schacter, D.L., Norman, K.A. \& Koutstaal, W. The cognitive neuroscience of constructive memory. Annu. Rev. Psychol. 49, 289-318 (1998).

19. Squire, L.R. Biological foundations of accuracy and inaccuracy in memory. in Memory distortion: How minds, brains, and societies reconstruct the past (ed. D.L. Schacter, J.T. Coyle, G.D. Fischbach, M.-M. Mesulam \& L.E. Sullivan) 197-225 (Harvard University Press, Cambridge, MA, 1995).

20. Bernstein, D.M., \& Loftus, E.F. How to tell if a particular memory is true or false. Perspectives Psychol. Sci. 4, 370-374 (2009).

21. Schacter, D.L. \& Slotnick, S.D. The cognitive neuroscience of memory distortion. Neuron 44, 149-160 (2004).

22. Schacter, D.L., Chamberlain, J., Gaesser, B. \& Gerlach, K. Neuroimaging of true, false, and imaginary memories. in Memory and Law (ed. L. Nadel \& W.P. Sinnott-Armstrong) 233-262 (Oxford University Press, New York, NY, 2012).

23. Straube, B. An overview of the neuro-cognitive processes involved in the encoding, consolidation, and retrieval of true and false memories. Behav. Brain Functions 8, 35 (2012). http://www.behavioralandbrainfunctions.com/content/8/1/35

24. Abe, N., et al. Neural correlates of true memory, false memory, and deception. Cereb. Cortex 18, 2811-2819 (2008).

25. Guerin, S.A., Robbins, C.A., Gilmore, A.W. \& Schacter, D.L. Interactions between visual attention and episodic retrieval: Dissociable contributions of parietal regions during gist-based false recognition. Neuron 75, 1122-1134 (2012).

26. Schacter, D.L., et al. Neuroanatomical correlates of veridical and illusory recognition memory: Evidence from positron emission tomography. Neuron 17, 267-274 (1996).

27. Slotnick, S.D. \& Schacter, D.L. A sensory signature that distinguishes true from false memories. Nature Neurosci. 7, 664-672 (2004).

28. Gonsalves, B., et al. Neural evidence that vivid imagining can lead to false remembering. Psychol. Sci. 15, 655-660 (2004).

29. Kensinger, E.A. \& Schacter, D.L. Neural processes underlying memory attribution on a reality-monitoring task. Cereb. Cortex 16, 1126-1133 (2006). 
30. Baym, C.L. \& Gonsalves, B.D. Comparison of neural activity that leads to true memories, false memories, and forgetting: An fMRI study of the misinformation effect. Cognit., Affect. Behav. Neurosci 10, 339-348 (2010).

31. Okado, Y.\& Stark, C.E. Neural activity during encoding predicts false memories created by misinformation. Learn. Mem. 12, 3-11 (2005).

32. Stark, C.E., Okado, Y. \& Loftus, E.F. Imaging the reconstruction of true and false memories using sensory reactivation and the misinformation paradigms. Learn. Mem. 17, 485-488 (2010).

33. Schooler, J.W., Gerhard, D. \& Loftus, E.F. Qualities of the unreal. J. Exp. Psychol.: Learn. Mem. Cognit. 12, 171-181 (1986).

34. Gutchess, A.H. \& Schacter, D.L. The neural correlates of gist-based true and false recognition. Neuroimage 59, 3418-3426 (2012).

35. Garoff-Eaton, R.J., Kensinger, E.A., \& Schacter, D.L. The neural correlates of conceptual and perceptual false recognition. Learning and Memory14, 684-692 (2007).

36. McDermott, K.B., Szpunar, K.K. \& Christ, S.E. Laboratory-based and autobiographical retrieval tasks differ substantially in their neural substrates. Neuropsychologia 47, 2290-2298 (2009).

37. Rissman, J., Greely, H.T. \& Wagner, A.D. Detecting individual memories through the neural decoding of memory states and past experience. Proc. Natl. Acad. Sci, U S A 107, 9849-9854 (2010).

38. Chua, E.F. Evaluating confidence in our memories: Results and implications from neuroimaging and eye movement monitoring studies of metamemory. in Memory and Law (ed. L. Nadel \& W.P. Sinnott-Armstrong) 119-141 (Oxford University Press, New York,NY, 2012).

39. Greely, H.T. \& Illes, J. Neuroscience-based lie detection: the urgent need for regulation. Am. J. Law Med. 33, 377-431 (2007).

40. Rosenfeld, J.P., Ben-Shakhar, G. \& Ganis, G. Detection of concealed stored memories with psychophysiological and neuroimaging methods. in Memory and Law (ed. L. Nadel \& W.P. Sinnott-Armstrong) 263-303 (Oxford University Press, New York, NY, 2012).

41. Abe, N. How the brain shapes deception: an integrated review of the literature. The Neuroscientist 17, 560-574 (2011).

42. Ganis, G., Rosenfeld, J.P., Meixner, J., Kievit, R.A., \& Schendan, H.E. Lying in the scanner: cover countermeasures disrupt deception detection by functional magnetic resonance imaging. NeuroImage 55, 312-319 (2011).

43. Garoff-Eaton, R.J., Slotnick, S.D. \& Schacter, D.L. Not all false memories are created equal: The neural basis of false recognition. Cereb. Cortex 16, 1645-1652 (2006). 
44. Garry, M., Manning, C., Loftus, E.F. \& Sherman, S.J. Imagination inflation: Imagining a childhood event inflates confidence that it occurred. Psychonomic Bull. Rev. 3, 208-214 (1996).

45. Goff, L.M. \& Roediger, H.L., III. Imagination inflation for action events- Repeated imaginings lead to illusory recollections. Mem. Cognit. 26, 20-33 (1998).

46. Schacter, D.K., Addis, D.R., Hassabis, D., Martin, V.C., Spreng, R.N., \& Szpunar, K.K. The future of memory: Remembering, imagining, and the brain. Neuron, 76, 677-694 (2012).

47. Edelson, M., Sharot, T., Dolan, R.J. \& Dudai, Y. Following the crowd: Brain substrates of long-term memory conformity. Science 333, 108-111 (2011).

48. Lee, J.L. Reconsolidation: Maintaining memory relevance. Trends Neurosci. 32, 413-420 (2009).

49. Agren, T., et al. Disruption of reconsolidation erases a fear memory trace in the human amygdala. Science 337, 1550-1552 (2012).

50. Hupbach, A., Hardt, O., Gomez, R. \& Nadel, L. The dynamics of memory: contextdependent updating. Learn. Mem. 15, 574-579 (2008).

51. Schiller, D., et al. Preventing the return of fear in humans using reconsolidation update mechanisms. Nature 463, 49-53 (2010).

52. St. Jacques, P.L. \& Schacter, D.L. Modifying memory: Selectively enhancing and updating personal memories for a museum tour by reactivating them. Psychol. Sci. (In press).

53. Gazzaniga, M.S. Neuroscience in the courtroom. Sci. Am. 304, 54-59 (2011).

54. State v. Nelson, $11^{\text {th }}$ Fl. Cir. Ct., F05-846 (2010).

55. Brown, T. \& Murphy, E. Through a scanner darkly: functional neuroimaging as evidence of a criminal defendant's past mental states, Stan. L. Rev. 62 1119-1208 (2010).

56. McCabe, D.P. \& Castel, A.D. Seeing is believing: The effect of brain images on judgements of scientific reasoning. Cognition 107, 343-352 (2008).

57. McCabe, D.P., Castel, A.D. \& Rhodes, M.G. The influence of fMRI lie detection evidence on juror decision-making. Behav. Sci. Law 29, 566-577 (2011).

58. Schweitzer, N.J., Saks, M.J., Murphy, E.R., Roskies, A.L., Sinnott-Armstrong, W., \& Gaudet, L. Neuroimages as evidence in a mens rea defense: No impact. Psychol. Public Policy Law 17 357-373 (2011).

59. Laris, M. Debate on brain scans as lie detectors highlighted in Maryland murder trial. in Washington Post (August 26, 2012). 